\title{
A história e o acervo das obras raras da Biblioteca de Manguinhos
}

\author{
The bistory of Biblioteca de \\ Manguinhos and its rare \\ collections
}

\author{
Maria Élide Bortoletto \\ Mestre em administração pública pela Fundação Getúlio Vargas, \\ pesquisadora da Fundação Oswaldo Cruz \\ Rua Vinicius de Moraes, 197/101 \\ 22411-010 Rio de Janeiro - RJ Brasil \\ melide@fiocruz.br e melide@terra.com.br \\ Marilene Antunes Sant'Anna \\ Mestranda em história social da Universidade Federal do Rio de Janeiro (UFRJ) \\ m.a.santana@bol.com.br
} O artigo descreve a formação do acervo de obras raras da Biblioteca de Manguinhos, da
Fundação Oswaldo Cruz. São obras que se estendem dos séculos XVII ao XX, distribuídas
entre livros, coleções de periódicos, folhetos, teses, que contemplam valiosos trabalhos
na área da história das ciências biológicas e da saúde. Descreve também a riqueza
ornamental e decorativa do ambiente e do mobiliário preservados da biblioteca. Resgata
a trajetória de 100 anos da Biblioteca de Manguinhos, intimamente associada à história
da Fundação Oswaldo Cruz.

PALAVRAS-CHAVE: obras raras, coleções científicas, história das ciências biomédicas, divulgação da informação

This article narrates the creation of Fundação Oswaldo Cruz Biblioteca de Manguinhos (Manguinhos Library) and its rare collections of books, magazines, journals, brochures, leaflets and theses, important publications on the history of biological sciences and health from the seventeenth to the twentieth century. It also describes the rich original ornaments and decoration of the library room and its furniture. It recovers the bistory of the library these past hundred years, which is closely associated to the history of Fundação Oswaldo Cruz.

KEYWORDS: rare collections, scientific collections, bistory of bio-medical sciences, unfolding information

Quando me falam de coleção, digo que não sou colecionador: eu tenho uma biblioteca, em que o fulcro é a leitura. Na formação da biblioteca, acabam se formando coleções, porque se lê um 
livro de um autor, gosta-se desse livro e vai-se querer ver as outras obras desse autor. Daí passa-se às primeiras edições, e então procuram-se exemplares autografados, depois entra a questão das raridades, e aí estamos perdidos. Mas a origem disso tudo deve ser o interesse pela leitura.

(Mindlin, 1999, p. 101).

\section{Introdução}

To ano 2000, durante as comemorações dos cem anos da Fundação 1 Oswaldo Cruz (Fiocruz) e dos quinhentos anos do Descobrimento do Brasil, o Centro de Informação Científica e Tecnológica (CICT) da Fiocruz apresentou duas exposições, Terra e Gente do Brasil e A Ciência e a Saúde Pública, que enfocaram a produção escrita e visual em torno da elaboração e evolução do conhecimento científico no mundo e no Brasil. Destacaram-se livros, revistas, desenhos, gravuras, fotos e manuscritos pertencentes ao acervo da Seção de Obras Raras Assuerus Overmeer da Biblioteca de Manguinhos.

A seção, localizada no Castelo Mourisco, abriga, em grande parte, um conjunto documental das primeiras décadas do século XX, constituído simultaneamente ao início das atividades do Instituto Soroterápico Federal, designado, a partir de 1908, Instituto Oswaldo Cruz (IOC). A classificação e localização dos títulos entre as obras raras obedecem alguns critérios importantes, como, por exemplo, a data, a originalidade dos textos e ilustrações, a demanda pela obra ou a existência de edições clandestinas ou especiais, que, em seu conjunto, tornam ainda mais irresistíveis o interesse pelo livro e sua leitura. ${ }^{1}$

Atualmente, a Seção de Obras Raras possui cerca de setenta mil volumes, dos quais oito mil são livros, sessenta mil periódicos e dois mil distribuem-se entre teses, manuscritos e folhetos. São obras que se estendem cronologicamente dos séculos XVII ao XX. A parte de periódicos dispõe de 604 títulos nacionais e internacionais, sendo que alguns existem somente nesta biblioteca. As teses são em sua maioria das faculdades de Medicina do Rio de Janeiro e da Bahia, e quase todas foram trabalhos dos pesquisadores do instituto. Os folhetos comportam descrições as mais variadas, podendo ser, por exemplo, um suplemento de revista ou um panfleto de propaganda de medicamento ou instituição.

Abrangendo os mais diversos campos do conhecimento, o acervo dispõe de obras representativas das ciências biológicas, principalmente nas áreas da botânica, zoologia, farmacologia, genética e das ciências da saúde, com ênfase nas áreas da medicina, da farmácia e da saúde

\footnotetext{
${ }^{1}$ São muitos os critérios bibliográficos ou bibliológicos que determinam a raridade de um livro. Sobre o assunto, ver Rodrigues (1996).
} 
coletiva. Outras possibilidades de pesquisa estão relacionadas às investigações de cunho histórico, oferecendo o acervo contribuições para se pensar o campo da história das ciências, que se reportam tanto ao estudo das obras científicas clássicas estrangeiras como a formação e trajetória deste campo no Brasil.

Com o objetivo de ampliar o número de leitores e possibilitar melhor conhecimento das obras desse acervo, está sendo desenvolvido, desde 1999, o projeto 'Ciência, natureza, saúde: um olhar construído a partir das obras raras da Biblioteca de Manguinhos' envolvendo dois departamentos do CICT, o Departamento de Estudos em Ciência e Tecnologia e a própria biblioteca. Acreditamos que a divulgação desse conjunto documental, de reconhecido valor histórico e científico, que permaneceu por muito tempo desconhecido e inacessível na própria instituição, permitirá um efeito multiplicador sobre a qualidade e o volume das pesquisas produzidas nos campos das ciências biomédicas, da saúde pública e da história das ciências no Brasil. Nesse sentido, este artigo pretende chamar atenção para a formação e diversidade do acervo, resgatando um pouco da trajetória da Biblioteca de Manguinhos e apresentando algumas das coleções já catalogadas. Além disso, veiculamos informações úteis sobre o funcionamento da seção, a fim de consolidá-la como um importante espaço de consulta e pesquisa para estudantes, professores e pesquisadores.

\section{História}

Em 1900, juntamente com a criação do Instituto Soroterápico Federal, chegaram os primeiros livros e revistas que seriam os embriões do acervo da Biblioteca de Manguinhos. Eram, sobretudo, exemplares de uma variedade de produções impressas na Europa, desde raridades dos séculos anteriores, a revistas trazendo as mais recentes descobertas científicas. Muitos desses volumes faziam parte das coleções particulares dos pesquisadores da instituição. Outros haviam sido comprados no comércio da cidade do Rio de Janeiro, que, no início do século XX, verificava um crescimento em torno da compra e venda de obras estrangeiras e nacionais (Ferreira, 1995; Schapochnik, 1999). Na quantidade de livros e revistas tinha-se nitidamente uma ampliação no número de publicações em língua estrangeira. Com maior freqüência, percebe-se os volumes em língua francesa e alemã, seguidos de outros em inglês, latim e português. Na divisão por área de conhecimento destacam-se livros e revistas de variados campos, com um pequeno aumento dos trabalhos de microbiologia, parasitologia, zoologia, entomologia e botânica.

$O$ início do funcionamento da biblioteca foi em um barracão localizado próximo à construção do futuro Pavilhão Mourisco. O lugar servia de depósito para livros e revistas e era também espaço de reunião dos pesquisadores que discutiam, uma vez por semana, os artigos mais 
interessantes e atuais que chegavam a Manguinhos. Nos trabalhos que tratam da história do IOC, como, por exemplo, no artigo de Henrique Aragão (1950, p. 16), citado a seguir, são recorrentes as atenções que Oswaldo Cruz voltava para a biblioteca, inclusive selecionando os artigos que deveriam ser resumidos e comentados nessas reuniões: "Tinha Oswaldo Cruz o trabalho de marcar, em cada revista, as publicações mais importantes assinalando o nome daquele que as deveria ler para resumi-las na sessão a realizar-se, semanalmente. E neste mister ia também orientando o assunto conforme as tendências e predileções que observava em seus discípulos."

Em 1903, nos esboços para a edificação do Castelo Mourisco, incluiuse um espaço para a biblioteca, que veio a merecer especial atenção em seus aspectos arquitetônicos e decorativos, e que permanece preservado até os dias de hoje. A biblioteca conta com um salão de leitura e uma ala onde fica guardado o acervo. O ambiente que, segundo muitos autores, é o lugar de maior riqueza ornamental do Pavilhão Mourisco, reforça o estilo oriental presente em todo o castelo. Dentre muitos aspectos chamam atenção as paredes e o teto trabalhados em gesso branco, as estalactites dos arcos suspensos do teto, o assoalho formando desenhos geométricos com diferentes tons de madeira e, no âmbito dos detalhes, distinguem-se as luminárias laterais feitas na Alemanha, em ferro fundido e bronze dourado com acessórios em opalina lilás. O mobiliário de época é em madeira castanho-escura e está presente na grande mesa retangular do salão de leitura, onde as revistas eram expostas semanalmente, nas oito mesinhas destinadas a consulta dos leitores, nos dois armários longos divididos em pequenos compartimentos onde ficavam armazenadas as revistas recém-chegadas e nos dois balcões usados para atendimento.

As obras, separadas do salão de leitura por uma porta ornamentada com vitrais, ficam guardadas em um conjunto de estantes de aço, à prova de fogo e insetos, disposto em quatro andares, fabricado e instalado, em 1913, pela Library Bureau de New York.

No ano de 1909, Oswaldo Cruz convidou o bibliófilo Assuerus Hippolytus Overmeer ${ }^{2}$ para organizar o acervo e exercer as funções de primeiro bibliotecário-chefe da Biblioteca de Manguinhos. Overmeer teve uma administração marcante à frente da biblioteca. Cuidou da organização do acervo no novo espaço e adquiriu catálogos e outros recursos técnicos de acesso às coleções, adotando a classificação decimal de Bruxelas, que até hoje é utilizada com a denominação de classificação decimal universal. Em 1946, a direção da Biblioteca de Manguinhos foi assumida por Emilia Machado de

\footnotetext{
${ }^{2}$ Overmeer era holandês, naturalizado brasileiro, e possuía grande experiência no campo da biblioteconomia. Iniciou suas atividades em Manguinhos em dezembro de 1909, onde permaneceu até fevereiro de 1944, vindo a falecer em dezembro do mesmo ano.
} 
Bustamante, que permaneceu no cargo até 1965, retornando a essa função no período de 1971 a 1976. A nova bibliotecária conseguiu expandir o acervo, ampliando sobretudo a permuta de periódicos, marca registrada do crescimento do acervo da Biblioteca de Manguinhos. Lecionou nos cursos de pós-graduação e de especialização do IOC e da Universidade Federal do Rio de Janeiro (UFRJ) e publicou vários trabalhos, entre eles o primeiro Catálogo de Periódicos da Biblioteca do Instituto Oswaldo Cruz no ano de 1959.

Sobre o acervo, ao longo dos seus cem anos de história, a Biblioteca de Manguinhos vivenciou uma progressiva expansão e enriquecimento. Em 1909, existiam cerca de três mil volumes e o número de periódicos cresceu de 98 do início do século para 421 títulos. ${ }^{3}$ Em 1944, o acervo já contava com noventa mil volumes e cerca de 2.600 títulos de revistas, recebendo aproximadamente mil consultas por mês. Em 1957, a biblioteca possuía o total aproximado de 160 mil volumes, com 4.300 títulos de periódicos e uma média de 19 mil consultas por ano (Bustamante, 1963). Já em 1965 a biblioteca atingia 4.536 títulos de periódicos com 273 mil volumes e daí para os atuais oitocentos mil volumes divididos em 34 mil volumes de monografias (livros, dissertações, teses, obras de referência) e sete mil títulos de periódicos, dos quais 1.566 são correntes. Dispõe ainda, em suas atuais instalações, das principais bases de dados na área das ciências da saúde e uma videoteca com cerca de 1.200 títulos. Foram atendidos no ano 2000 aproximadamente 35 mil usuários.

Já na década de 1940, o problema do espaço físico era preocupante. Com o crescimento do acervo, principalmente das revistas, que vinham de inúmeras instituições e países do mundo, a biblioteca estendeu-se para outras salas ao seu redor, até que na década de 1960 já ocupava todo o terceiro andar do Castelo Mourisco. Nas décadas seguintes, a documentação ficou armazenada em diferentes lugares, inclusive no recém-inaugurado Instituto Nacional de Controle de Qualidade em Saúde (INCQS), para onde foram transferidas as coleções de periódicos correntes e obras de referência. Somente os exemplares mais antigos permaneceram no Castelo. Em 1986, com a criação do CICT e mais tarde, com a construção do Pavilhão Haity Moussatché — prédio que hoje congrega a Biblioteca de Manguinhos - , o problema da guarda e preservação do acervo finalmente pareceu resolvido.

Em meados da década de 1980, através principalmente de um convênio com a Financiadora de Estudos e Projetos (Finep), teve início

\footnotetext{
${ }^{3} \mathrm{O}$ aumento do número de títulos do acervo da Biblioteca de Manguinhos sempre esteve associado ao sucesso das atividades científicas e de saúde pública realizadas pela Fiocruz. Por exemplo, no início, em 1907, o recebimento da medalha de ouro pelo IOC na Exposição Internacional do XIV Congresso de Higiene e Demografia de Berlim, pelas campanhas de saneamento do Rio de Janeiro, teve reflexos positivos para a biblioteca, repercutindo no aumento considerável de títulos por doação ou permuta.
} 
o projeto de identificação e tratamento das obras raras em meio a todo o acervo da Biblioteca de Manguinhos. A seção foi batizada com o nome de Assuerus H. Overmeer em homenagem ao primeiro bibliotecário da instituição. E, como resultado desse projeto, foi publicado, em 1992, o Catálogo de Obras Raras e Especiais da Biblioteca de Manguinhos, uma coletânea de referências bibliográficas e bibliológicas de 182 livros do acervo.

A transferência para o novo edifício, em 1995, constituiu um processo integrado de ações que se desenvolveram em duas direções. Por um lado, a biblioteca preocupou-se em ter os olhos voltados para o futuro, adequando-se às novas políticas e tecnologias de informação, e, por outro, não deixou de considerar seu passado, como depositária das tradições de ensino e pesquisa científicas durante um século de história. Em nossos dias, o CICT e a Biblioteca de Manguinhos se empenham em criar condições necessárias para garantir a recuperação e disseminação da informação científica de acordo com as necessidades de seus diversos públicos. Os resultados envolvem a contínua ampliação do acervo, a disponibilização da informação de forma rápida e eficiente, através de publicações impressas, bancos de dados, sites da Internet, bibliotecas virtuais etc. e a constante preocupação com a preservação e restauração das obras. Como nos lembra o historiador Roger Chartier (1999), vivemos em uma época de revolução do texto eletrônico com a expectativa de que a Internet e o livro eletrônico substituam o sistema impresso dos séculos da época moderna. Porém, o mais provável, segundo o mesmo autor, para os próximos decênios é a coexistência entre o suporte físico do livro e o mundo digital da comunicação. Daí, a importância de se refletir sobre a preservação e integração da forma antiga dos livros, e também de revistas, jornais e textos em geral, com as novas modalidades do processo de produção e transmissão da informação.

\section{O acervo}

A Seção de Obras Raras Assuerus H. Overmeer vem se transformando em importante centro de documentação científica, referendada por pesquisadores da instituição e visitantes, ao reunir fontes de pesquisa dos séculos XVII ao XX no âmbito de diferentes áreas do conhecimento científico.

Entre os itens do acervo, destacam-se raridades como o livro Historia naturalis Brasiliae (Amsterdam, 1648), de Piso e Marggraf, naturalistas que vieram ao Brasil a convite de Maurício de Nassau durante o período da ocupação holandesa no Nordeste. O livro, como sabemos, foi considerado o primeiro escrito sobre história natural do Brasil e seus textos e ilustrações serviram de base para outros trabalhos que se seguiram, alguns dos quais produzindo importantes obras de referência, como foi o caso do Systema Naturae (Estocolmo, 1758), de Carl von 
Lineu, ${ }^{4}$ e da coleção de Flora Brasiliensis (Leipzig, 1840-1906), de von Martius. ${ }^{5}$

Outros livros encontrados no acervo são: Experimenta circa generation insectorum (Amsterdam, 1671), de Francesco Redi (162697), Memoires pour servir a l'histoire des insectes (Paris, 1734-42), de René Ferchault de Reaumur (1683-1757), Systema Entomologiae (Alemanha, 1775), de Johan C. Fabricius (1745-1808), três tratados pioneiros sobre a fisiologia dos insetos no campo da biologia moderna. O acervo possui trabalhos de conhecidos naturalistas franceses, alemães e ingleses, como, por exemplo, Georges-Louis Leclerc de Buffon (170778), Karl Jablonsky (1756-87), Thomas Martyn (1735-1825), Pierre Latreille (1762-1883) e Paul Gervais (1816-79). Sobre os portugueses que vieram para o Brasil, lembramos as obras de Manuel Aires de Casal (17541821), que escreveu Corografia brazilica (1817), do médico e cirurgião português Luis Gomes Ferreira, autor de Erário mineral(1735), importante estudo sobre patologia e terapêutica no Brasil colonial, de Antonio Ladislau Monteiro Baena (1781-1850), militar e historiador, que escreveu Compêndio das eras da província do Pará (1838), de Henrique Veloso de Oliveira (1804-67), magistrado e escritor, que escreveu Systema de materia medica vegetal brasileira (1854). A produção dos brasileiros, dividida entre médicos, magistrados, escritores, padres e cientistas, registra importantes contribuições para a ciência no país, como, por exemplo, José Mariano da Conceição Veloso (1742-1811), Ladislau Netto (1838-94) que, enquanto diretor do Museu Nacional, foi um dos fundadores do periódico Archivos do Museu Nacional, existente entre as obras raras da Seção Overmeer, e João Barbosa Rodrigues (18421909), naturalista, fundador do Museu Botânico do Amazonas e diretor do Jardim Botânico do Rio de Janeiro. São também dignos de nota autores como José Pereira Rego (1816-92), Joaquim Monteiro Caminhoá (1836-96), João Vicente Torres Homem (1837-87), Francisco de Castro (1857-1901), expoentes da Academia Imperial de Medicina e da Faculdade de Medicina do Rio de Janeiro. ${ }^{6}$

Na Seção Overmeer, o leitor encontrará um manuscrito, de 1703, que reúne receitas para variadas doenças, como, por exemplo, varíola, sífilis e tuberculose, ou para incômodos que acometiam os indivíduos da colônia brasileira nos primeiros séculos, como azia, impotência, cólicas ou dor de dente. Os ensinamentos, atribuídos aos jesuítas,

\footnotetext{
${ }^{4}$ A Seção de Obras Raras, além desse trabalho clássico de Lineu (1707-78), possui mais 13 obras do mesmo autor.

${ }^{5}$ A obra que demorou 66 anos para ser completada baseou-se em material recolhido pelo próprio von Martius em viagem ao Brasil, junto com Spix e outros da comitiva da arquiduquesa d. Leopoldina.

${ }^{6}$ Para uma descrição mais apurada de títulos de livros e autores do acervo, consultar Catálogo de Obras Raras e Especiais da Biblioteca de Manguinhos (Rio de Janeiro, Fiocruz, 1992).
} 
recomendam o uso das plantas medicinais e também as práticas das sangrias e purgantes recorrentes de toda a medicina ocidental.

Do século XIX são significativos os livros e atlas de viajantes que percorreram o Brasil e outros países da América Latina, em busca do conhecimento das terras e dos povos do novo mundo. Entre os viajantes mais conhecidos, possuímos obras de Alexander von Humboldt (17691859), Maximiliam von Wied (1782-1867), Auguste de Saint-Hilaire (1779-1853), Johann Baptist von Spix (1781-1827), Karl Friedrich von Martius (1794-1868), Louis Agassiz (1807-73), entre muitos outros. Sobre os viajantes descobertos por uma produção recente nessa temática, sobretudo de historiadores, lembramos as obras de François Auguste Biard (1798-1882), Hermann Burmeister (1807-92), Henry Coster (17931820) e Jean Théodore Descourtilz, todas ricamente ilustradas e com textos importantes sobre fauna, flora e costumes dos povos dos países visitados.

No acervo encontram-se também referências importantes à teoria evolucionista. O alicerce mais sólido para esse tema desenvolveu-se por meio das pesquisas e escritos de Charles Darwin (1809-82), principalmente através de seu texto revolucionário The origin of species by means of natural selection, que a Seção de Obras Raras possui, além de mais sete outras obras deste mesmo autor. Outras obras de importantes cientistas que discutiram a evolução das espécies, como Jean-Baptiste Lamarck (1744-1829), Xavier Bichat (1711-1802), Alfred Wallace (18231913), Fréderic G. Cuvier (1773-1838), Richard Owen, Gregor Mendel (1822-84), encontram-se também disponíveis. A partir do final do século XIX, destacamos os trabalhos de Thomas Morgan (1866-1945), Edward M. East (1879-1938), Walter Sutton (1877-1916), que deram início ao desvendamento do campo da genética.

Em relação ao conjunto de periódicos, convém dizer que está sendo realizada a compilação do primeiro Catálogo de Periódicos Científicos Raros da Biblioteca de Manguinhos. O projeto, com apoio da Fundação de Amparo à Pesquisa do Estado do Rio de Janeiro (Faperj), mapeou todos os títulos do acervo procedendo no momento ao seu inventário. A parte de periódicos impressiona pela diversidade de títulos, áreas de conhecimento, períodos e instituições. Compreende, no total, 604 títulos entre revistas, coleções de anuários, relatórios. Na impossibilidade de citar a relação integral dos títulos, escolhemos alguns que, pela demanda dos usuários ou por sua relevância como fonte de pesquisa, nos mostram a validade da preservação e disseminação desse acervo.

Referência importante são os periódicos internacionais, como, por exemplo, os Annales de Chimie et de Physique (Paris, 1789-1913), Annalen der Physick (Leipzig, 1790-1983), Proceedings of the Royal Society of London (Londres, 1800-1969), Lancet (Londres, desde 1823), American Journal of Medicinal Science (Estados Unidos, 1891-1997), Actes de la Société Linnéenne de Bordeaux (1838-1930), Annales de la Société Entomologique de Belgique (1857-1924), Boletim da Academia 
das Ciencias de Lisboa (Lisboa, 1914-16). Chamam ainda atenção as revistas: Nouvelle Iconographie de la Salpêtrière (Paris, fundado em 1888) publicado sobre a direção do prof. Charcot —; trata-se de um periódico fartamente ilustrado, que divulgava as internações e o tratamento dado aos alienados no hospital do mesmo nome - Annales de L'Institut Pasteur, cujo primeiro tomo é de 1887, disponível na seção até o ano de 1923; Archives de Médecine Navale (Paris, 1864-1910), e depois sua continuação com o nome de Archives de Médecine et Pharmacie Navales, até 1918; Annales d'Hygiène Publique et de Médecine Légale (Paris, 1829-1907).?

Destacamos a existência de inúmeros periódicos latino-americanos, como, por exemplo, Boletin de la Salud Publica (Montevidéu, 193245), Revista de Higiene (Bogotá, 1933-42), Revista de Medicina Legal de Cuba (Havana, 1922-31), Anales del Museo Nacional Buenos Aires (Buenos Aires, 1905-17), Revista del Museo de La Plata (periódico da Universidade Nacional de La Plata, Buenos Aires, 1891-1927), Revista Chilena de Historia Natural (revista do Museo de Historia Natural de Valparaiso, Santiago do Chile, 1900-30), Anales Cientificos Paraguayos (Puerto Bertoni, 1901-19).

Quanto às publicações nacionais, o acervo conta, por exemplo, com as Memórias do Instituto Oswaldo Cruz (Rio de Janeiro, desde 1909), Gazeta Médica da Babia (Salvador, 1877-1972), Brazil-Médico (Rio de Janeiro, 1887-1971), Boletim da Academia Nacional de Medicina (Rio de Janeiro, 1919-29) Boletim do Museu Paraense Emilio Goeldi de História Natural e Ethnografia (Pará, 1900-08), Revista Médica de Minas (1908-22), editada pela classe médica de Juiz de Fora, que contava com Carlos Chagas, Antonio Austregésilo e Moncorvo Filho entre seus colaboradores.

O acervo possui trabalhos que, além de contribuírem para a produção e divulgação das ciências biológicas e da saúde, versam sobre cultura, geografia, história e política do Brasil, como algumas obras de cronistas como Jean de Léry (Histoire d'un voyage fait en la terre du Brésil, 1880) e Rocha Pita (História da America portugueza, 1880) ou ainda de escritores e historiadores como Robert Southey (História do Brazil, 1862), Francisco Adolfo de Varnhagen (História Geral do Brazil, 1852) e Alphonse de Beauchamp (Histoire du Brésil, depuis as découvert en 1500 jusqu'en 1810, 1815).

Dispõe a seção de coleções conhecidas por reeditarem livros antigos sobre a história e cultura brasileiras. A primeira delas é a Série Brasiliana, publicada pela Companhia Editora Nacional a partir de 1931, responsável pela permanência de obras que, desde o século XVI, formam os clássicos do pensamento social brasileiro, e também a coleção Documentos

\footnotetext{
${ }^{7}$ O local e as datas entre parênteses indicam o lugar de publicação e os anos de início e fim do periódico no acervo.
} 
Brasileiros, da José Olympio, lançada a partir de 1936, e a Biblioteca Histórica Brasileira, da Livraria Martins, fundada em 1940.

Lembramos aos leitores que a Seção de Obras Raras Assuerus Overmeer fica localizada no terceiro andar do Castelo Mourisco da Fundação Oswaldo Cruz. O horário de atendimento é de segunda a sexta-feira, das $8 \mathrm{~h}$ às $17 \mathrm{~h}$. A seção funciona como espaço de consulta e pesquisa, para estudantes de graduação e pós-graduação, docentes, pesquisadores, e como espaço de desenvolvimento de projetos de natureza artístico-cultural, veiculados sobretudo através de exposições temáticas abertas a todos os visitantes.

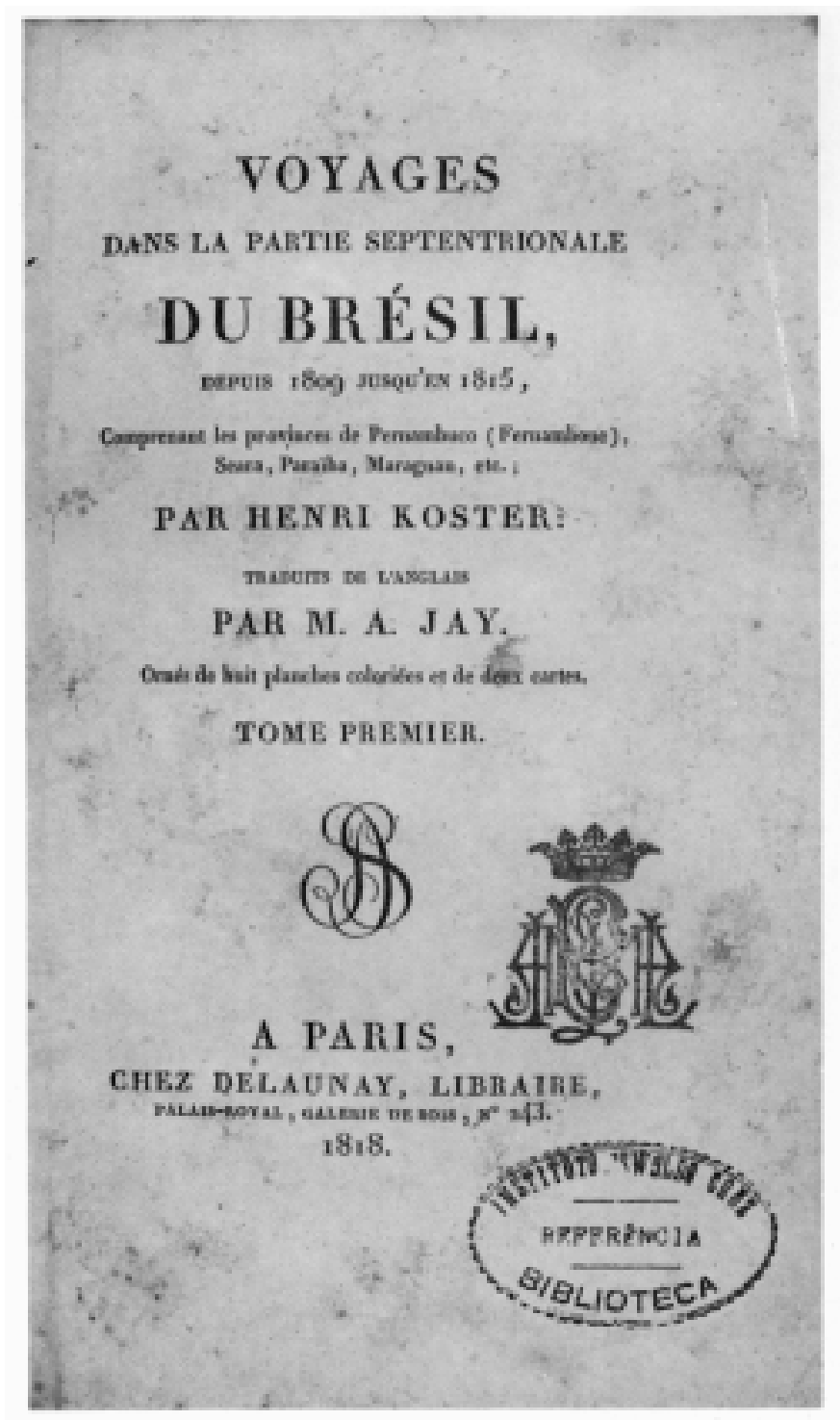

Henry Koster, Voyages dans la partie septentrionale du Brésil, depuis 1809 jusqu'en 1815. Paris, 1818, (ref. no 63 do COR, pp. 57 e139). 


\section{Raturinftem}

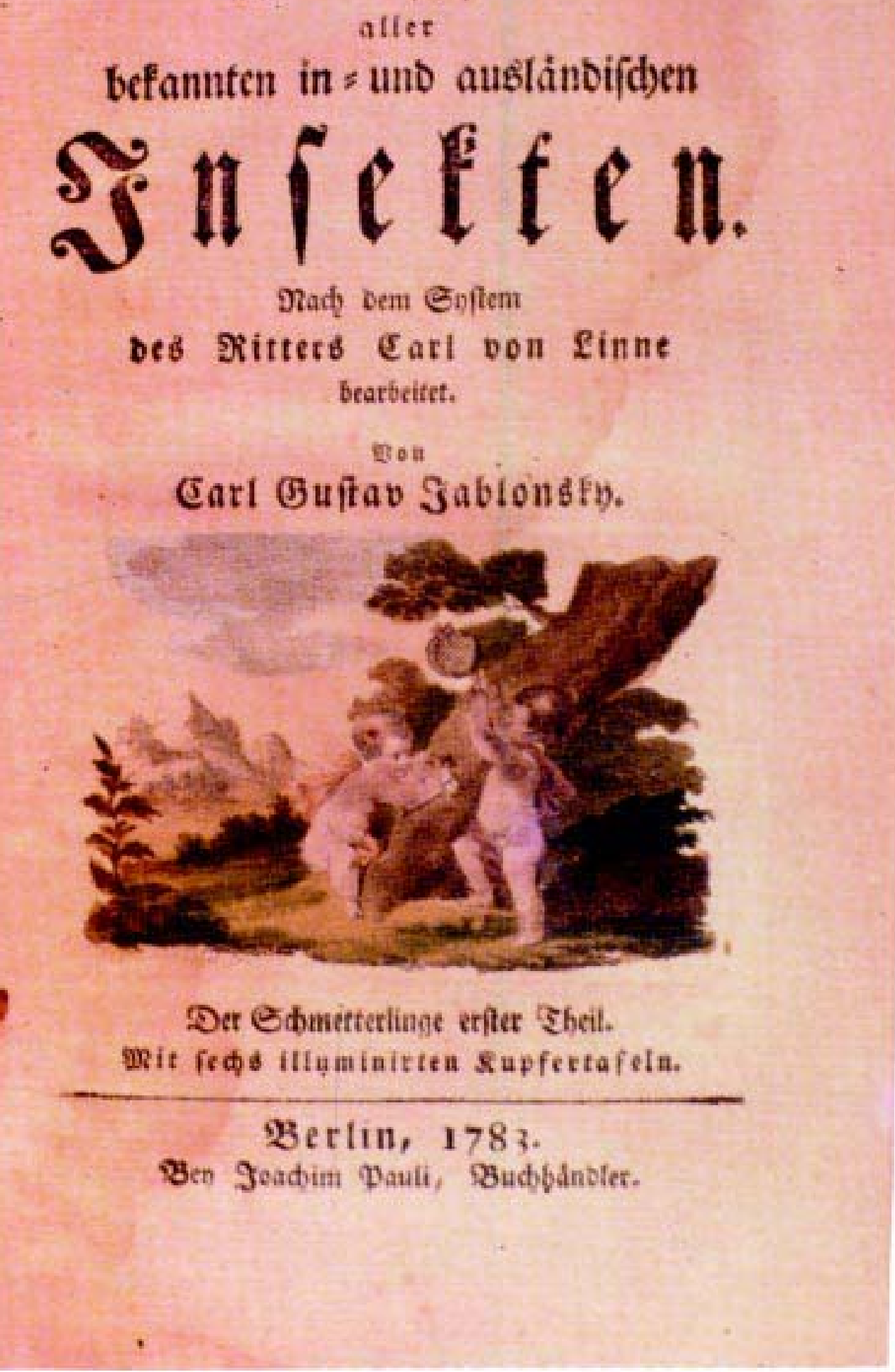

Karl Gustav Jablonsky e Johann Friedrich Wilhelm Herberst, Natursystem aller bekannten in-und ausländischen Insekten, Berlim, 1783. 


\title{
OSSERVAZIONI
}

D 1

FRA NCESCO REDI

\author{
ACCADEAIICO DELLA CRVSCA.
}

I N T O R N O

AGLI ANIMALI VIVENTI

CHE SI TROVANO-Gxhelim NEGLI ANIMALI VIVENTI?
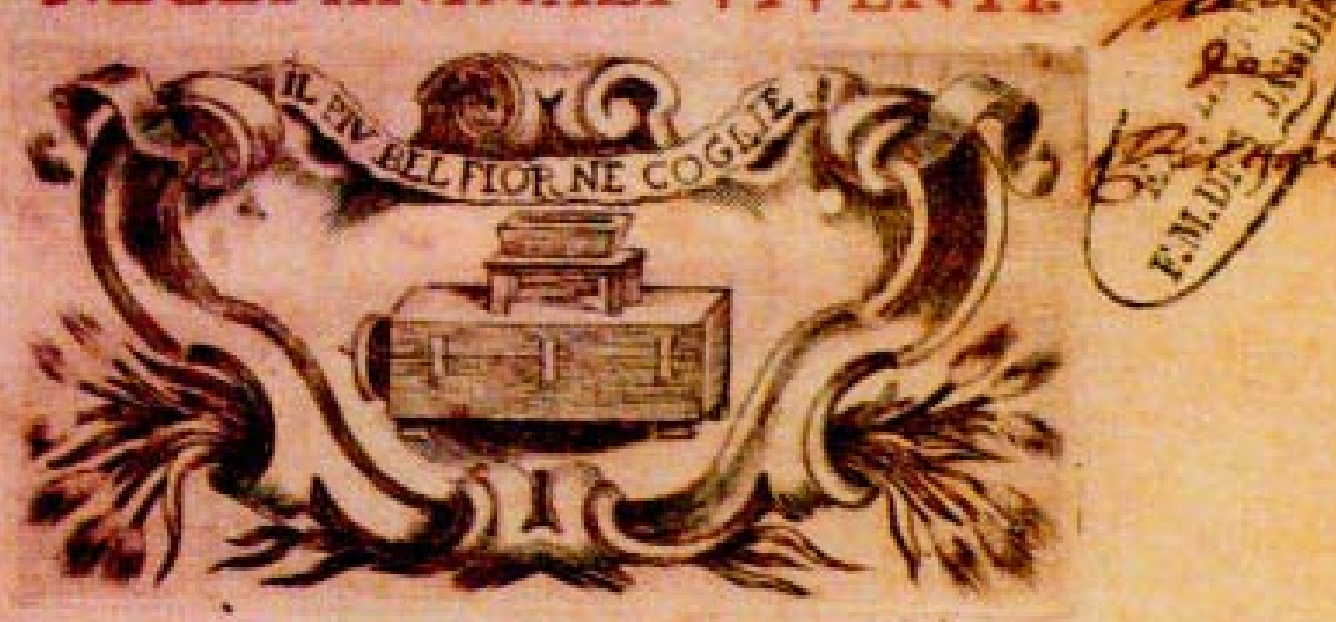

IN FIR̃ENZE, MDCIXXXIV.

Per Piero Matini, all infegna del Lion d' Oro. Con licans de' Superiori.

Francesco Redi, Osservazioni di Francesco Redi...intorno Agli Animália Viventi che si trovano Negli Animali Viventi, Florença, 1684 (ref. no 4 do COR, pp. 29, 141). 


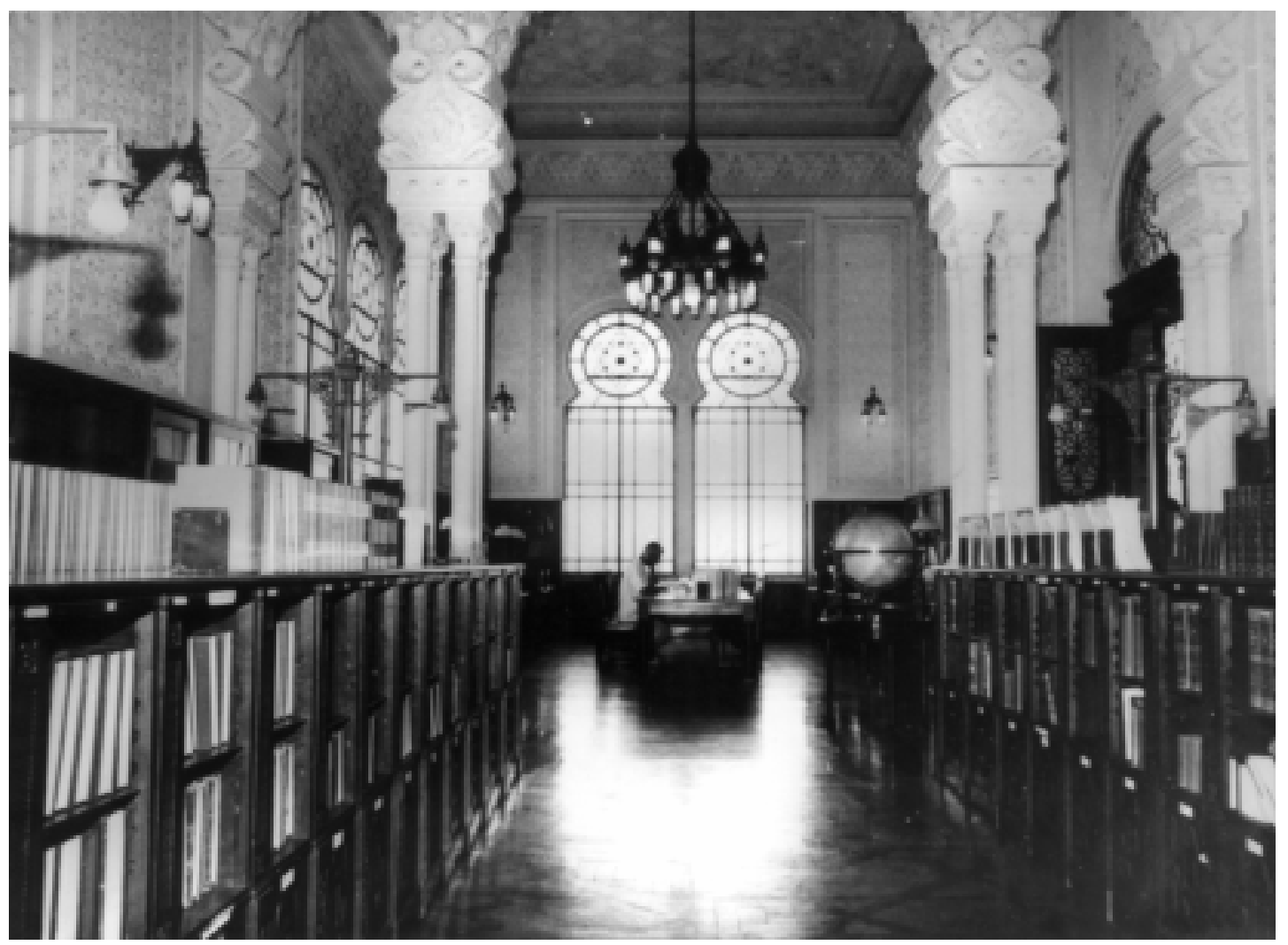

Seção de Obras Raras Assuerus Overmeer, década de 1970.

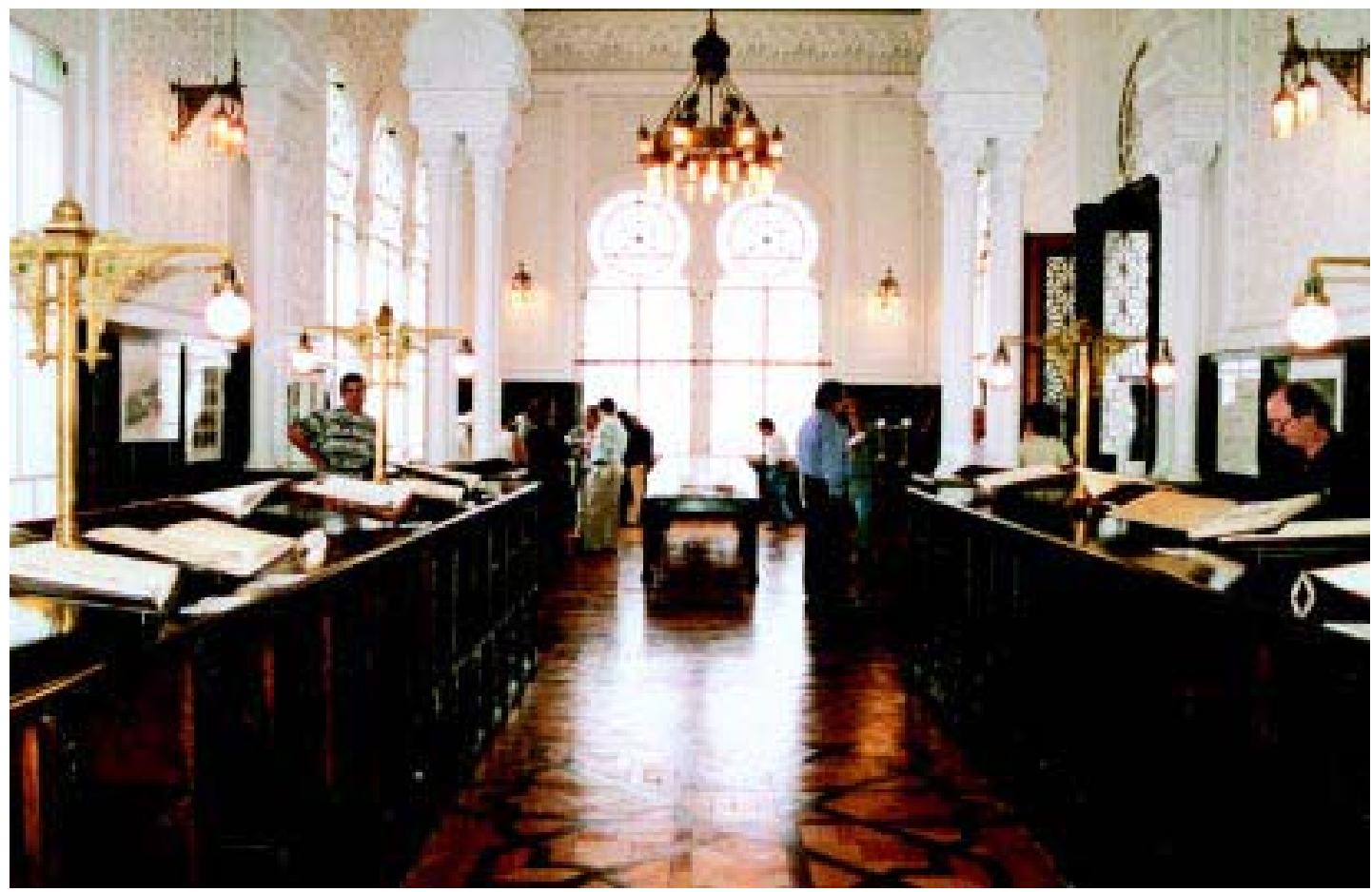

Seção de Obras Raras Assuerus Overmeer (ambiente restaurado na década de 1990). 


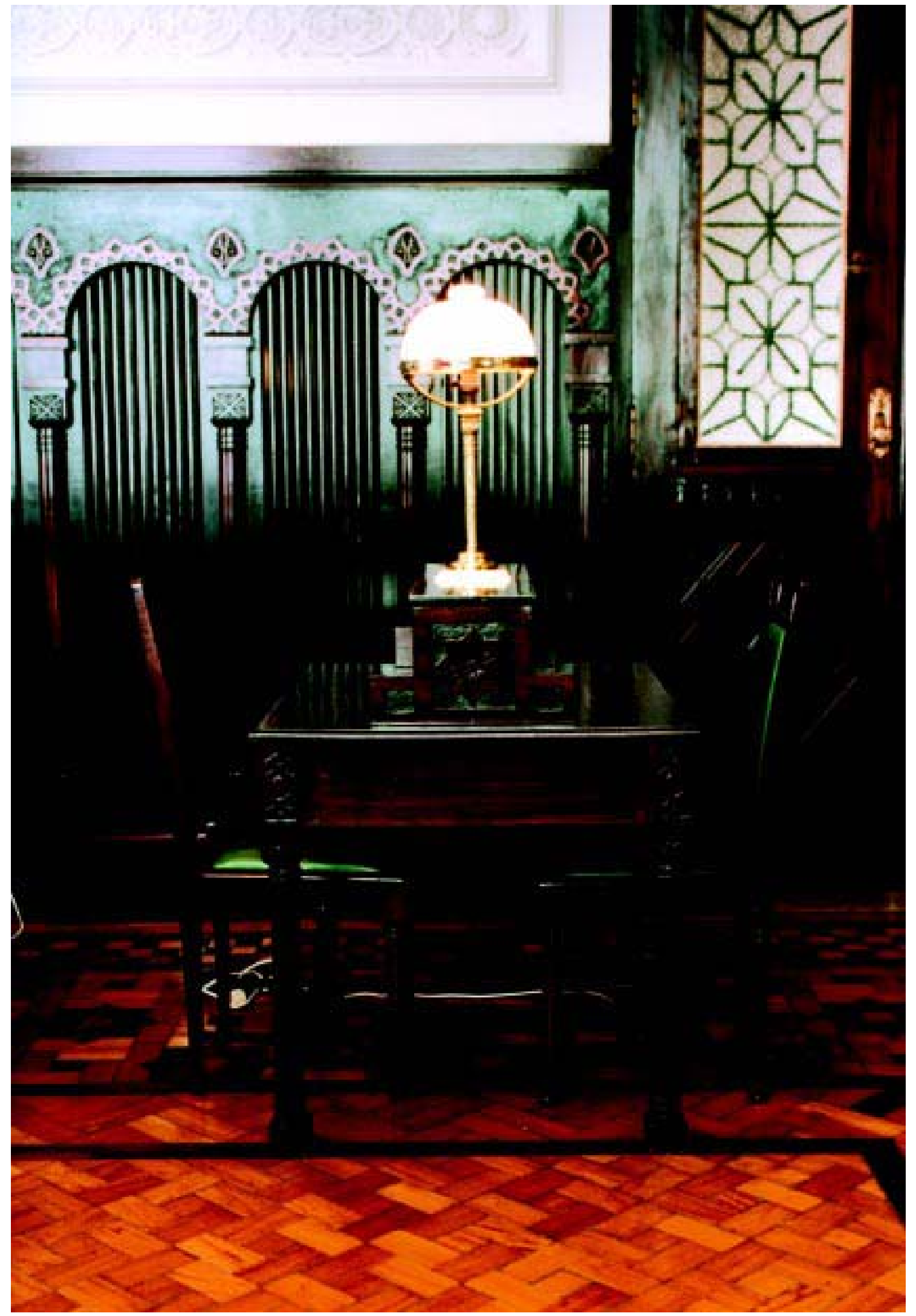

Mesa de leitura da Seção de Obras Raras Assuerus Overmeer (mobiliário restaurado na década de 1990). 


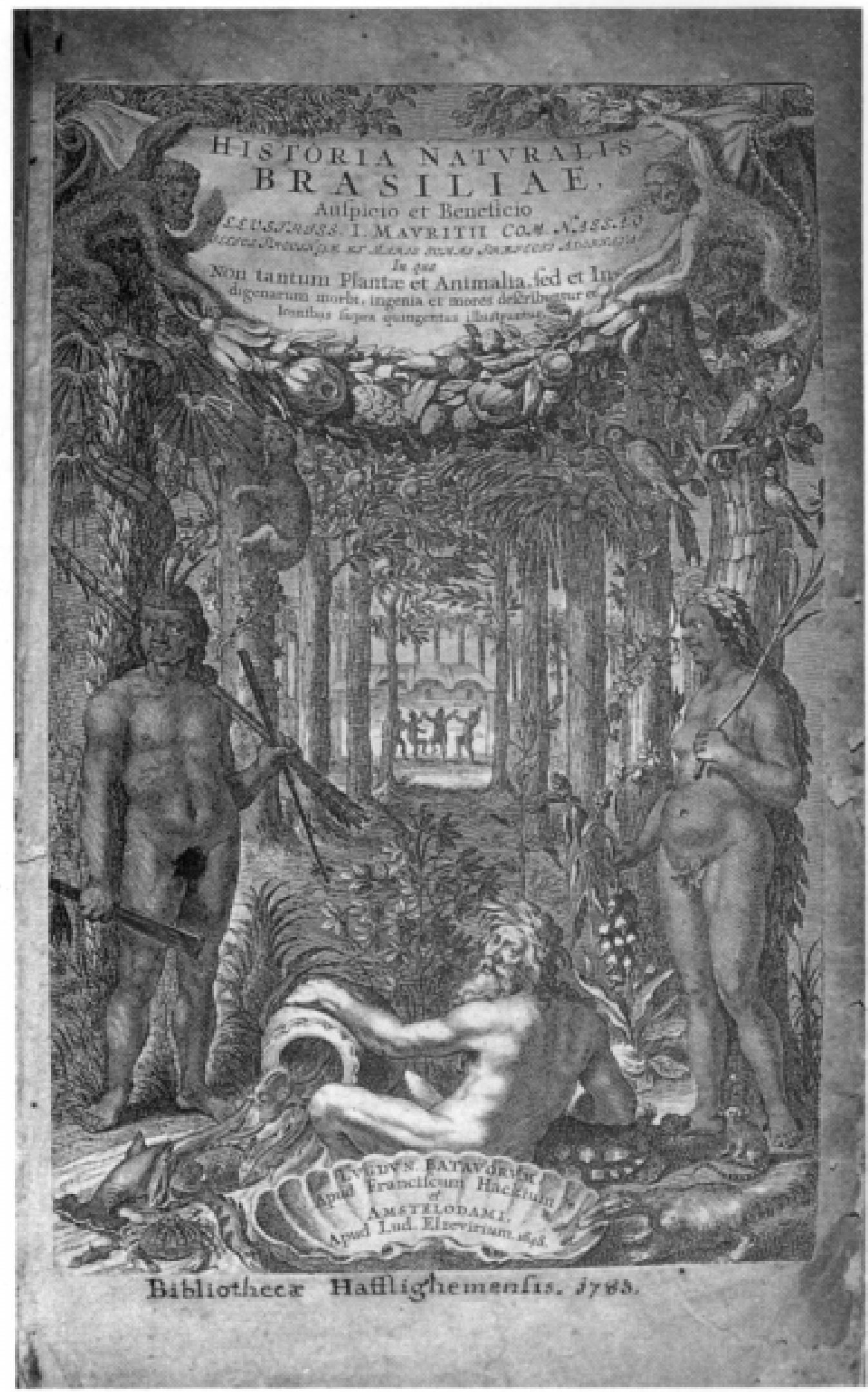

Willem Piso e Georg Marggraf, Historia Naturalis Brasiliae, Holanda, 1648 (ref. no 1 do COR, pp. 27, 137). 


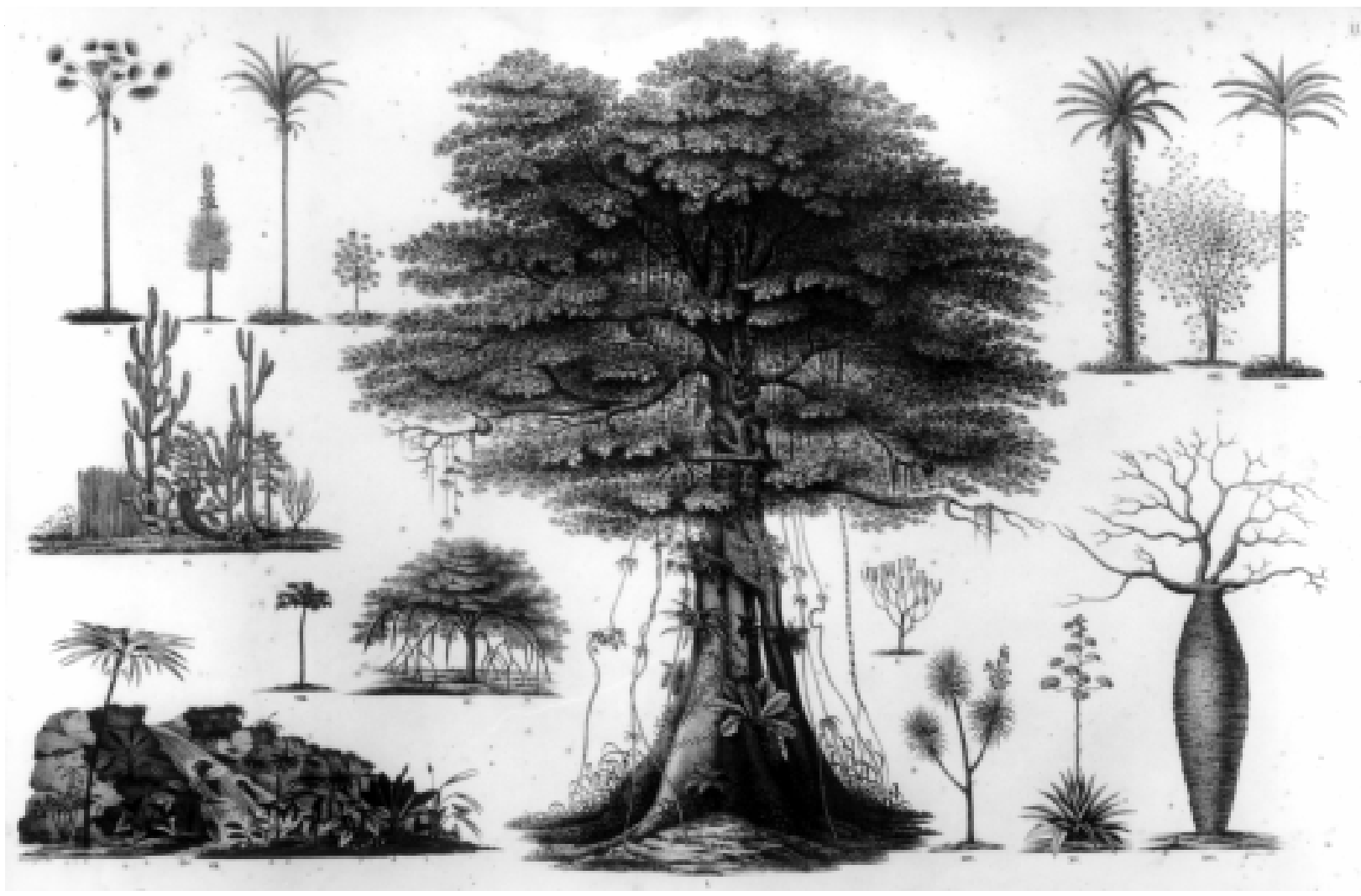

Johann Baptist von Spix e Karl Friedrich Philipp von Martius, Reise in Brasilien auf Befehl Sr. Majestät Maximilian Joseph I, Königs von Baiern in den Jahren 1817 bis 1820, Baviera, 1823 (ref. no 73 do COR, p. 61).

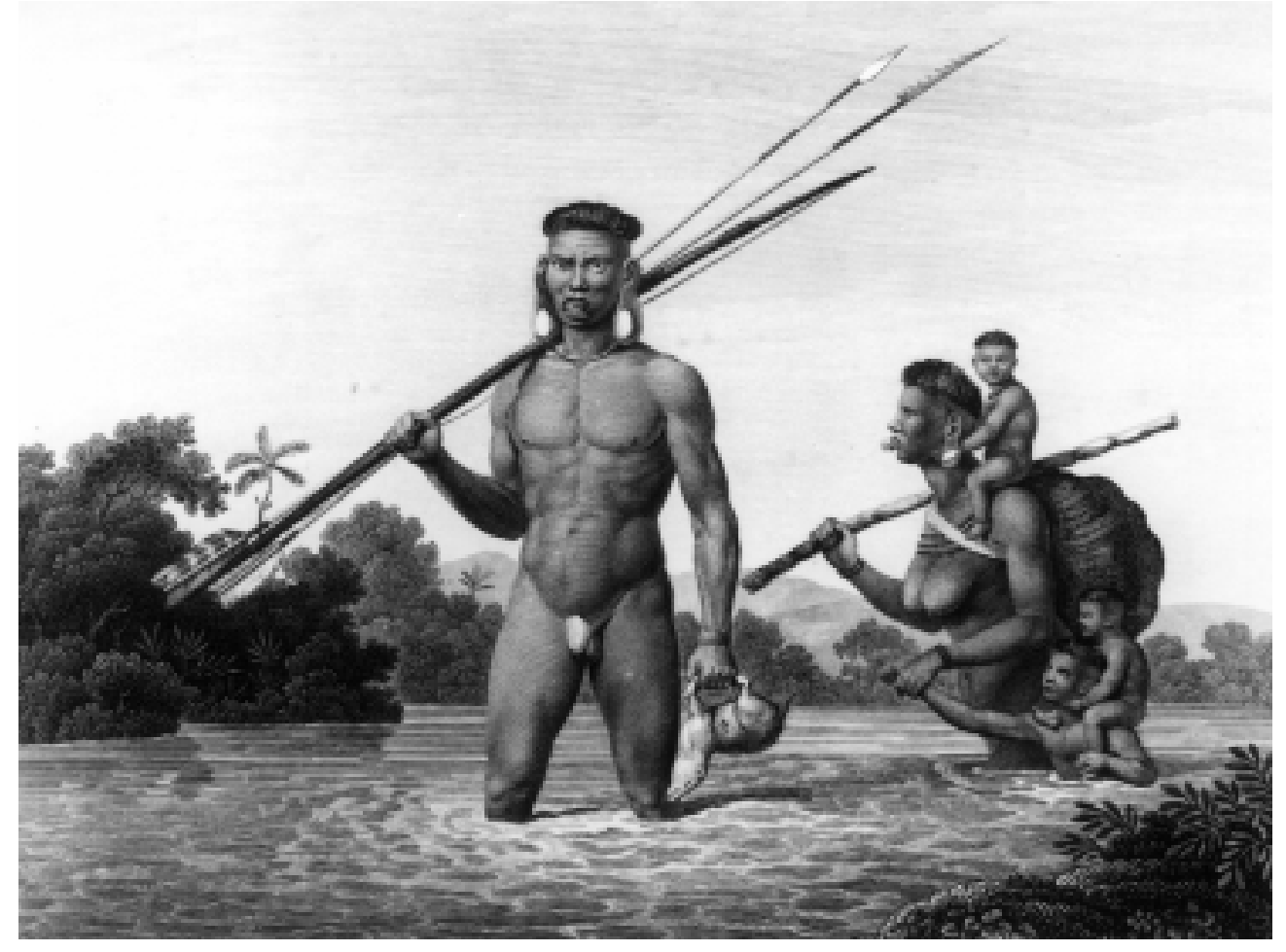

Príncipe Maximilian von Wied, Reiche naise Brasilien,

Alemanha, 1820

(ref. $\mathrm{n}^{\circ} 66$ do COR, pp. 58, 187). 


\section{REFERÊNCIAS BIBLIOGRÁFICAS}

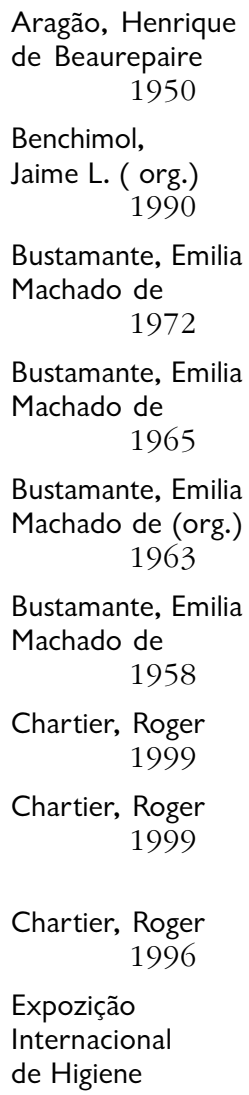

Benchimol, Jaime L. ( org.) 1990

Bustamante, Emilia Machado de 1972

Bustamante, Emilia Machado de 1965

Bustamante, Emilia Machado de (org.) 1963

Bustamante, Emilia Machado de 1958

Chartier, Roger 1999

Chartier, Roger 1999

Chartier, Roger 1996

Expozição Internacional de Higiene 1909

Ferreira, Tânia Maria T. B. da Cruz jan.-dez. 1995

Fonseca Filho, Olympio da 1974

Fonseca Filho, Olympio da 1966

Fonseca Filho, Olympio da 1925

Instituto Oswaldo Cruz 1900(?)

Rodrigues, Jeorgina Gentil 1996

Schapochnik, Nelson 1999

Superintendência de Informação Científica. maio de 1991
'Notícia histórica sôbre a fundação do Instituto Oswaldo Cruz (Instituto de Manguinhos)'. Memórias do Instituto Oswaldo Cruz, Rio de Janeiro, tomo 48, pp. 1- 50.

Manguinhos do sonho à vida: a ciência na belle époque.

Rio de Janeiro, Casa de Oswaldo Cruz.

Oswaldo Cruz: Opera Omnia.

Rio de Janeiro, Instituto Oswaldo Cruz.

Biblioteca do Instituto Oswaldo Cruz. Palestra realizada na Escola de Biblioteconomia e Documentação. Rio de Janeiro, 9p. (mimeo.)

Catálogo de Periódicos da Biblioteca do Instituto Oswaldo Cruz. Rio de Janeiro, Instituto Oswaldo Cruz.

As bibliotecas especializadas como fontes de orientação na pesquisa cientîfica. Rio de Janeiro, Instituto Oswaldo Cruz, 18p.

A aventura do livro: do leitor ao navegador. São Paulo, Editora Unesp/Imprensa Oficial do Estado.

'As revoluções da leitura no Ocidente'. Em Márcia Abreu (org.), Leitura, história e história da leitura. Campinas/São Paulo, Mercado de Letras/ Associação de Leitura do Brasil/Fapesp, pp. 19-33.

Culture écrite et societé: l'ordre des livres (XIV-XVIII siècle). Paris, Bibliothèque Albin Michel.

Expozição Internacional de Higiene anexa ao $4^{\circ}$ Congresso Medico Latino-Americano (Rio de Janeiro): $1^{\underline{0}}$ de agosto a 30 de setembro de 1909: Regulamento. Rio de Janeiro, Imprensa Nacional, 22p.

'Leitores do Rio de Janeiro: bibliotecas como jardins das delicias'. Acervo - Revista do Arquivo Nacional, vol. 8, n ${ }^{\circ}$ 1/2.

'A Biblioteca de Manguinhos'. Em A Escola de Manguinhos. Separata do tomo II de Oswaldo Cruz: Monumenta Histórica. São Paulo, Revista dos Tribunais.

Súmula das atividades do Instituto Oswaldo Cruz em dois anos: junho de 1964 a junho 1966. Rio de Janeiro, Instituto Oswaldo Cruz, (13) p. ilus.

Exposição feita pelos funcionários technicos do Instituto Oswaldo Cruz ao Exmo. sr. ministro do Interior e Justiça e aos homens publicos do paiz. Rio de Janeiro, Empreza Graphica Editora, 7p.

Instituto de Manguinhos, Rio de Janeiro.

Paris, J. David, (28) p. ilus.

O espelho do tempo: uma análise da coleção das obras raras da Fundação Oswaldo Cruz como fonte de pesquisa para a ciência moderna. Dissertação de mestrado, Rio de Janeiro, Universidade Federal do Rio de Janeiro.

'Das ficções do Arquivo: ordem dos livros e práticas de leitura na biblioteca pública da corte imperial'. Em Leitura, história e história da leitura. Campinas/ São Paulo, Mercado de Letras/Associação de Leitura do Brasil/Fapesp.

Biblioteca de Manguinhos. Prefeitura do Campus. Estudo para Implantação da Nova Biblioteca de Manguinhos. Rio de Janeiro, 14p. e anexos. 